\title{
FE Modelling of Mechanical Tensioning for Controlling Residual Stresses in Friction Stir Welds
}

\author{
D.G. Richards ${ }^{1}$, P.B. Prangnell ${ }^{1}$, P.J. Withers ${ }^{1}$, S.W. Williams ${ }^{2}$, A. Wescott ${ }^{3}$, \\ E.C Oliver ${ }^{4}$
}

\author{
${ }^{1}$ Manchester Materials Science Centre, UMIST, Grosvenor St. Manchester, M1 7HS, UK. \\ ${ }^{2}$ Now at Cranfield University, Welding Engineering Research Centre, Bedfordshire, MK43 OAL, UK. \\ ${ }^{3}$ BAE Systems, Optics and Laser Technology Department, Advanced Technology Centre, P.O. Box \\ 5, FPC 267, Bristol, BS12 7QW, UK. \\ ${ }^{4}$ ISIS Facility, CCLRC, Rutherford Appleton Laboratory, Chilton, Didcot, OX11 0QX, UK \\ david.g.richards@postgrad.manchester.ac.uk,philip.prangnell@manchester.ac.uk, \\ philip.withers@manchester.ac.uk,s.williams@cranfield.ac.uk, andrew.wescott@baesystems.com
}

Keywords: Friction Stir Welding; Residual Stress; FE Modelling; Neutron Diffraction; AA2024.

\begin{abstract}
Although Friction Stir Welding (FSW) avoids many of the problems encountered when fusion welding high strength Al-alloys, it can still result in substantial residual stresses that have a detrimental impact on service life. An FE model has been developed to investigate the effectives of the mechanical tensioning technique for controlling residual stresses in FSWs. The model purely considered the heat input and the mechanical effects of the tool were ignored. Variables, such as tensioning level, heat input, and plate geometry, have been studied. Good general agreement was found between modelling results and residual stress measurements, justifying the assumption that the stress development is dominated by the thermal field. The results showed a progressive decrease in the residual stresses for increasing tensioning levels and, although affected by the heat input, a relatively low sensitivity to the welding variables. At tensioning levels greater than $\sim 50 \%$ of the room temperature yield stress, tensile were replaced by compressive residual stresses within the weld.
\end{abstract}

\section{Introduction}

The development of Friction Stir Welding (FSW), a solid state welding method, has enabled the joining of high strength aluminium alloys that were previously considered unweldable [1]. Although FSW alleviates many metallurgical problems found with fusion welding, such as liquation and solidification cracking, friction stir welds can still suffer from similar levels of residual stress, resulting from the weld's local thermal field [2]. High residual stresses are a major concern in the aircraft industry, due to their 'knockdown' effect on in-service life, and are an obstacle inhibiting the application of FSW to airframes. Preliminary work by Williams, et al [2, 3] has shown that the application of additional tensioning stresses during the welding process can greatly reduce the residual stresses in FSW. In some cases, such as with the application of high levels of mechanical tensioning along the welding direction, the stress state in the weld can actually be reversed, so that compressive residual stresses are formed [2]. To date few systematic studies have been performed on the effectiveness of this method for controlling residual stresses in FSWs and, for example, the influence of the welding parameters is currently not known. Furthermore, although much modelling work has been carried out on the FSW process (e.g. [4-12]), there have been few models developed to predict the residual stresses generated and little, or no, modelling into the combined effects of welding stress development and mechanical tensioning.

In order to improve current understanding of the potential of mechanical tensioning, for controlling residual stresses in FSW airframe structures, a simplified FE model has been developed to simulate the process. The approach used and results from the model are presented in this paper. The model output is compared with previously obtained/published experimental data that was measured by $\mathrm{x}$-ray 
synchrotron diffraction at ESRF-ILL [13], and from subsequent calibration measurements made on further samples at ISIS-RAL using neutron diffraction as part of this investigation.

\section{FE Model and Heat Source Calibration}

The modelling approach adopted was based on the work of Q. Shi, et al [9] and M. Peel [14] and relied purely on the thermal field generated by the welding tool. The metal flow and mechanical effects of the tool were not considered. This simplification is computationally very helpful and has previously been found to give good results, as the formation of residual stresses in FSW is normally dominated by the heat input $[9,11,12,15,16]$. The model was implemented in ABAQUS using a sample geometry $(1135 \times 250 \times 3 \mathrm{~mm})$ that replicated the test coupons and clamping used to produce supporting experimental data at BAE Systems, ATC, Filton. The model comprised a single partitioned plate, representing the two separate plates to be welded, the partition line being along the weld line. A graded mesh was used with $1 \mathrm{~mm} \times 1 \mathrm{~mm} \times 3 \mathrm{~mm}$ elements at the weld line, which increased to $25 \mathrm{~mm} \times 25 \mathrm{~mm} \times 3 \mathrm{~mm}$ at the edge of the plate. The plate was pinned vertically along its length at $40 \mathrm{~mm}$ from the weld line to simulate clamping and the tension force was applied uniformly along one edge normal to the welding direction. The material and thermal-physical properties used were for a standard AA2024 alloy [17]. The FSW heat source was simulated by using a circular surface source, to represent the tool shoulder $\left(Q_{s}\right)$, and a cylindrical volume source, to represent the tool pin $\left(Q_{p}\right)$, which were traversed along the weld line using an ABAQUS subroutine. The distribution of the heat flux under the tool shoulder, $q_{s}$, at a radius, $r$, was assumed to be linear with angular velocity, based on the work of Y.J. Chao, et al $[4,5]$; given by:

$$
q_{s}(r)=\frac{3}{(2 \pi)} \frac{Q_{s} r}{\left(R_{s}^{3}-R_{p}^{3}\right)}
$$

Where $R_{s}$ and $R_{p}$ are the dimensions of the shoulder and pin. The heat input from the pin was assumed to be uniform with the pin depth and was assigned to be $12 \%$ of the total power, based on previous experience $[4,5,7,15,16]$ and calibration studies, with the remainder distributed under the shoulder. Heat loss was simulated using artificial surface convection coefficients [18] for each surface boundary condition to simulate conduction to the welding base-plate, retaining clamps, and to air. This method allowed the jigging parts to be omitted from the model, saving on simulation times. The thermal profile generated by the thermal model was used as an input to the mechanical model in the form of nodal temperatures.

Fig. 1. Example of a comparison of an experimentally measured (infrared; IR) maximum temperature thermal profile, recorded transverse to the welding direction, with that from the model for AA2024 using welding parameters of 770rpm and $195 \mathrm{~mm} / \mathrm{min}$.

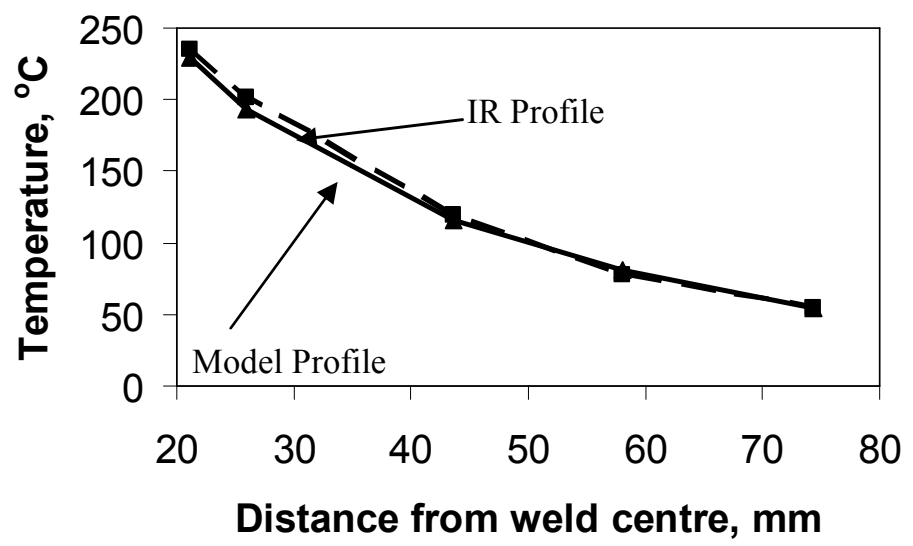

Calibration of the heat source and surface convection coefficients was achieved by matching thermal profiles, captured by an infrared thermal imaging camera obtained during the creation of the FSW test coupons, to the model output. The standard welding condition used was 770rpm and $195 \mathrm{~mm} / \mathrm{min}$. Several successive model simulations were run until a reasonable match was obtained 
(Fig. 1), resulting in a shoulder power input, $Q_{s}$, of $1120 \mathrm{~W}$ and a pin power input, $Q_{p}$, of $120 \mathrm{~W}$, giving a total power input of $1240 \mathrm{~W}$, to represent the welding parameters of $770 \mathrm{rpm}$ and $195 \mathrm{~mm} / \mathrm{min}$. This calibration method allowed the heat loss through the tool to be ignored (i.e. the actual tool power would be $\sim 40 \%$ higher). The thermal profile generated by this power input was then used for the simulated tensioning experiments. The heat input was subsequently systematically varied around this value within the constraints of the material melting and the temperature becoming unrealistically low.

\section{Results and Discussion}

Effect of Mechanical tensioning under standard welding conditions In welding, as the heat source advances, material ahead of the source expands and develops compressive stress, because it is constrained by the colder surrounding material. This stress largely plastically relaxes due to the low material yield stress at high temperatures $[13,19]$. The contracting hot metal behind the heat source, thus develops a misfit strain as it cools, resulting in a tensile residual stress that is maximum in the welding direction and balanced by a small far field compressive stress in the plate. The main effect of mechanical tensioning is therefore to raise the background tensile stress level and increase the relaxation of the stresses in the tensile zone generated on cooling behind the heat source. Tensioning also reduces the compressive strain in the zone ahead of the tool.

To investigate how effective this technique can be, mechanical tensioning loads were applied in the model simulations during welding, under the standard condition with the fitted heat source, using tensioning stress levels defined in terms of the percentage of the room temperature yield stress for AA2024 (325MPa). Examples of predicted longitudinal residual stress distributions from the model, in the plane of the plate surface, with and without any mechanical tensioning, are shown in Fig. 2a. Without tensioning the modelled stress distribution indicates a maximum tensile residual stress of $220 \mathrm{MPa}$ that occurs symmetrically and corresponds approximately with the edge of the tool shoulder, giving an 'M-shaped' profile. After removal of the tensioning load, the longitudinal residual stress profiles in Fig. 2a initially showed a progressive decrease in the maximum residual stresses, as a function of increasing tensioning level applied during welding. The model predicted that the maximum stresses remained tensile and the welds retained their ' $M$ - shaped' profile until a tensioning level of $\sim 50 \%$ of the yield stress was applied. At above this level the residual stresses started to develop in a compressive sense, forming a ' $\mathrm{V}$-shaped' profile with a maximum compressive stress at the weld centre line.
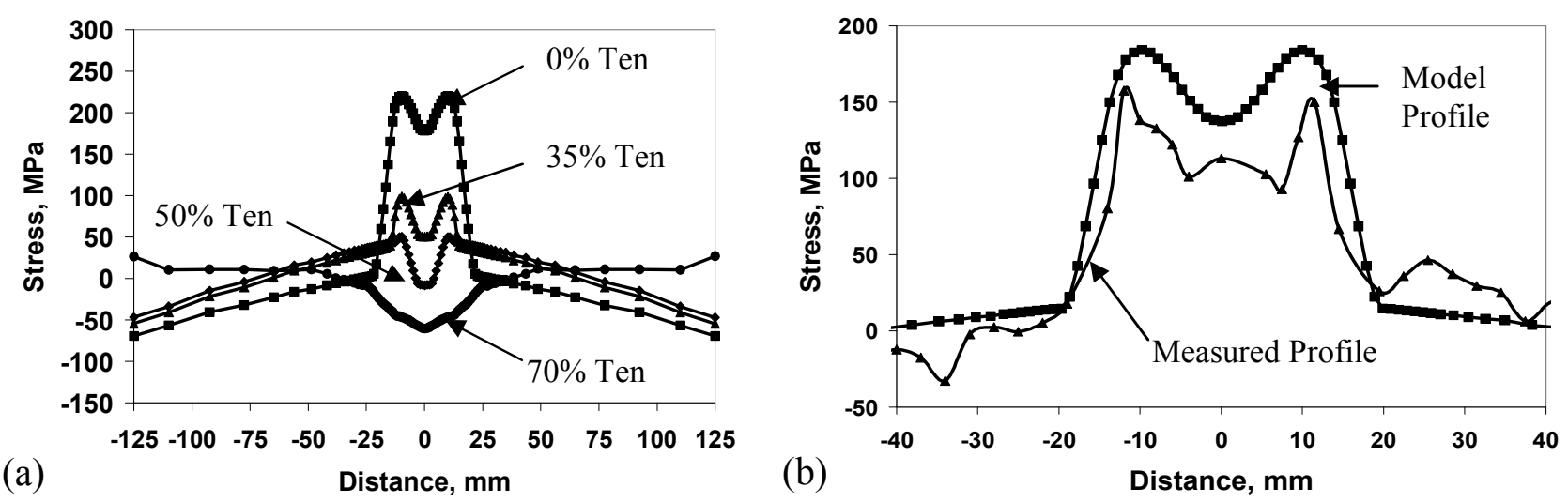

Fig. 2. Longitudinal stresses in (a) predicted from the model for an un-tensioned and tensioned (to $35 \%, 50 \%$ and $70 \%$ of yield stress) AA2024 plate, and in (b) for a 10\% tensioning level compared to neutron diffraction measurements, all using a heat input of $1240 \mathrm{~W}$ representing the welding parameters of $770 \mathrm{rpm}$ and $195 \mathrm{~mm} / \mathrm{min}$.

While in future work it is planned to measure residual stresses in coupons produced with identical geometry and welding conditions, in the short term preliminary experimental data was sought to 
verify these predictions. A comparison was therefore made with data provided by Price, et al [13] for the same geometry as the model, showing the effect of tensioning on the peak longitudinal stresses in AA2024 1m long welds determined from x-ray synchrotron diffraction measurements, with welding conditions of $350 \mathrm{rpm}$ and $195 \mathrm{~mm} / \mathrm{min}$. As part of the investigation a calibration comparison was also made using measurements obtained by neutron diffraction at ISIS-RAL, using an AA2024, $780 \times 400$ $\mathrm{x} 3 \mathrm{~mm}$, FSW sample that had been tensioned by $10 \%$ during welding under nearly identical conditions of $770 \mathrm{rpm}$ and $200 \mathrm{~mm} / \mathrm{min}$ to the calibrated heat source used in the model. The longitudinal stress profile from these measurements is compared in Fig. $2 b$ with modelling predictions for the same tensioning level. It can be noted from this figure that the model profile gives a very good reproduction of the measured profile, but the stresses are slightly over estimated, with values of $184 \mathrm{MPa}$, compared to $157 \mathrm{MPa}$ for the measured results. All of these results are depicted together in Fig. 3a, with the measured data giving similar trends to the model simulations, despite the different welding conditions and plate geometries.
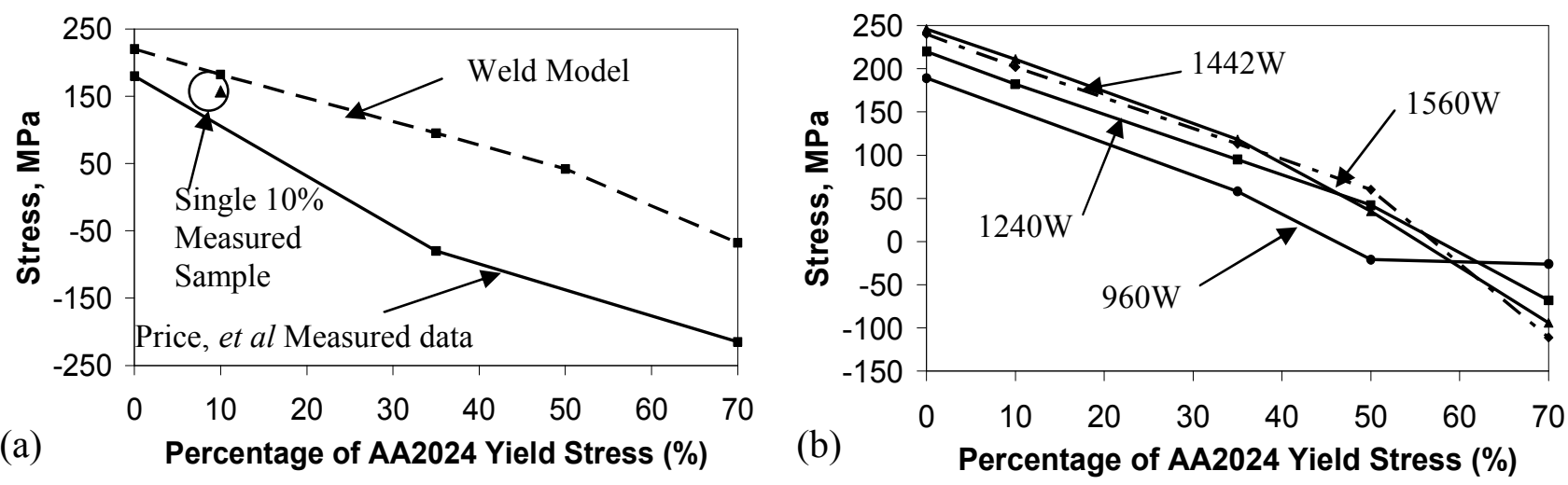

Fig. 3. Predicted values of maximum longitudinal residual stress, as a function of tensioning level, in terms of percentage of the yield stress, under the standard welding condition of 770 rpm and $195 \mathrm{~mm} / \mathrm{min}$, in (a) compared to a single $10 \%$ calibration sample with similar welding conditions, and data taken from Price, et al [13] using 350rpm and $195 \mathrm{~mm} / \mathrm{min}$; and in (b) results for simulated power inputs of $960 \mathrm{~W}, 1240 \mathrm{~W}, 1442 \mathrm{~W}$ and $1560 \mathrm{~W}$ for AA2024 (standard geometry).

Variations in clamping, plate geometry, and the welding parameters would be expected to contribute to the slightly differing magnitudes in the residual stress profiles, between the experimental and predicted curves. More importantly, the time dependence of the materials yield stress with temperature and the possibility of creep relaxation are not currently considered in the model, which thus tends to give an overestimate of the residual stresses. However, the same general trends seen in Fig. $3 \mathrm{a}$ and the close agreement between the single measured calibration sample available to date and the predicted results (Fig. 2b), where the welding parameters and geometry were practically identical, gives confidence in the robustness of the relatively simple model explored so far.

Effect of welding variables While, when more calibration data becomes available it will be possible to improve accuracy, at this stage the model appears sufficiently reliable to explore the trends that result from the influence of other welding variables on the effectiveness of the mechanical tensioning technique. To this end, simulations were first carried out to determine the effect on the residual stress distribution, at different tensioning levels, of changes in the heat input, which would result from altering the tool RPM. Total power input values of $960 \mathrm{~W}, 1442 \mathrm{~W}$, and $1560 \mathrm{~W}$ were selected to compare to the original total tool power of $1240 \mathrm{~W}$. The peak stress levels that result from these simulations are shown in Fig $3 \mathrm{~b}$. Without tensioning, the higher heat input results in slightly higher maximum residuals stresses, but as the tensioning level increases, the curves cross and reverse order with the higher heat input curves falling below those with a low heat input. This probably results from 
the far-field tensioning stress becoming more effective with increasing heat input, as it acts over an expanded volume of softer material in the zone behind the tool.

The effect of a higher rate of heat loss through the anvil was also simulated, by doubling the convection co-efficient applied to the anvil contact area, which would reduce the peak temperature reached at the bottom surface along the weld line under the tool and possibly have the opposite effect of increasing the power input. The predicted longitudinal residual stress distribution for this simulation is shown in Fig. 4, which should be compared to the original behaviour in Fig. 2a. The profiles indicate a decrease in stress level at the weld centreline in the weld nugget, but little change to the maximum values of the twin peaks at the edge of the TMAZ. When the tensioning stress is increased the effect of a more effective heat sink below the tool is small on the reduction in maximum residual stress levels that occurs.

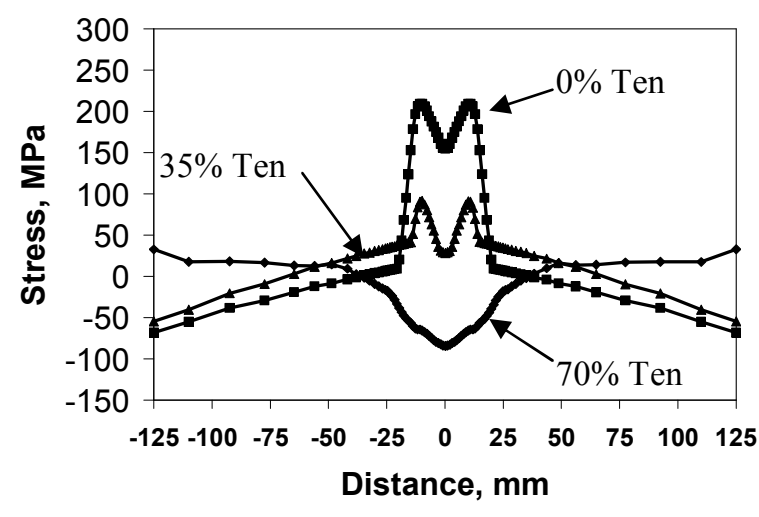

Fig. 4. Predicted longitudinal residual stresses (for $0 \%, 35 \%$ and $70 \%$ of yield stress of AA2024) using standard welding parameters, but with double the rate of heat loss to the anvil under the tool (compare to Fig. 2a).

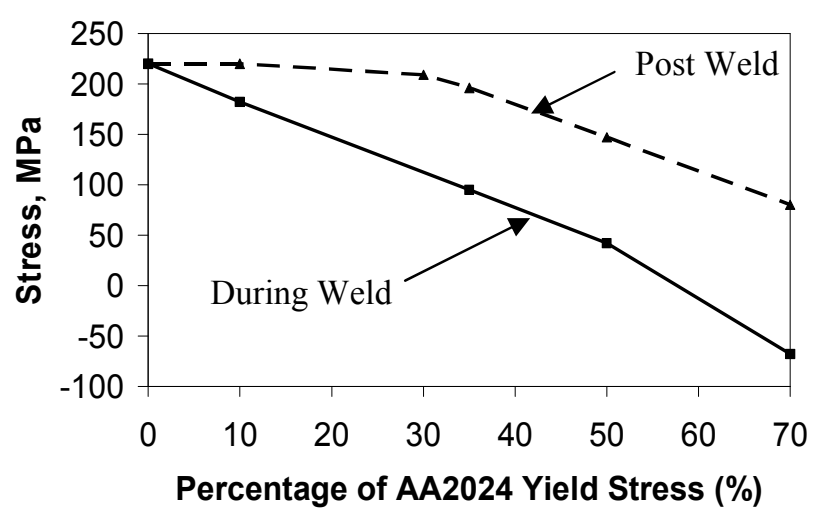

Fig. 5. Predicted values of max. longitudinal residual stress, as a function of tensioning level, for post-weld tensioning compared to the case where tensioning is applied during welding (as per Fig. 3) (standard welding conditions).

The effect of different weld geometries was also investigated by the creation of a model comprising a far shorter plate measuring $350 \mathrm{~mm} \times 250 \mathrm{~mm} \times 3 \mathrm{~mm}$, using the same tensioning range and power input $(1240 \mathrm{~W})$. The peak residual stresses were compared to the original model results and gave a very similar behaviour. The above analysis thus suggests that, in terms of the peak residual stresses, the most dominant parameter is the applied tensioning level and the process is very robust within the range which the welding parameters can be varied, as there is only a weak sensitivity to the welding variables.

A final investigation was carried out to adjust the model so that tensioning was applied after welding, rather than during the welding process. Predicted values of maximum longitudinal residual stress, as a function of tensioning level, under the standard welding condition for post-weld tensioning are compared to those obtained previously when tensioning is applied during welding in Fig. 5. These simulations clearly show that post-weld tensioning, when the whole sample is cold and has a much higher yield stress, is much less effective in shaking down the residual stresses than when mechanical tensioning is applied during the welding process.

\section{Conclusions}

The residual stress model developed, based purely on the FSW tool thermal field, showed reasonable agreement with published data and a calibration sample measured by neutron diffraction. In general the model proved to be a good tool for the investigation of the effectiveness of mechanical tensioning for controlling residual stresses in FSW's. The simulations and measurements showed a progressive decrease in the residual stresses with increasing tensioning applied during welding. This continued 
until $50 \%$ of the yield stress at room temperature was exceeded, at which point the tensile stresses in the weld were eliminated and replaced by increasing levels of compressive stresses. Tensioning applied after welding was found to be much less effective, with little response until approximately $30 \%$ of the yield stress was exceeded. Comparisons between different power inputs (representing different welding parameters) and different geometries all produced consistent results, and showed that the peak stresses, although influenced by the heat input, were not dramatically affected by the welding conditions.

\section{Acknowledgements}

This work is supported through the University of Manchester EPSRC Light Alloys Portfolio Partnership (EP/D029201/1) in collaboration with Airbus UK.

\section{References}

1. W.M. Thomas and E.D. Nicholas: Materials and Design, 1997. 18(4-6): p. 269-273.

2. P. Staron, M. Kocak, S.W. Williams and A. Wescott: Physica B: Condensed Matter, 2004. Volume 350(Issues 1-3, Supplement 1, 15 July 2004,): p. Pages E491-E493.

3. S.W. Williams, D.A. Price., A.Wescott, C.J. Harrison, P.Staron and M. Kocak., 2004.

4. Y.J. Chao and X. Qi: 1st International Symposium on FSW.1999. Thousand Oakes: TWI.

5. Y.J. Chao, X. Qi and W. Tang: Journal of Manufacturing Science and Engineering, 2003. 125(1): p. 138-145.

6. M. Song and R. Kovacevic: International Journal of Machine Tools and Manufacture, 2003. 43(6): p. 605-615.

7. W. Tang, X.G., J.C. McClure and L.E. Murr: Journal of Materials Processing \& Manufacturing Science, 1999. 7(2): p. 163172.

8. P. Ulysse: International Journal of Machine Tools and Manufacture, 2002. 42(14): p. 1549-1557.

9. Q. Shi, T. Dickerson and H.R. Shercliff: 4th International Symposium on FSW (cd rom), Utah, USA, TWI, 2003.

10. C.M. Chen and R. Kovacevic: International Journal of Machine Tools and Manufacture, 2003. 43(13): p. 1319-1326.

11. P.A. Colegrove: Dissertation in Department of Mechanical Engineering, University of Adelaide, 2001.

12. P.A. Colegrove and H.R. Shercliff: Cambridge. p. Draft document, 2005.

13. D. Price, C.J. Harrison, S.W. Williams, A. Wescott, A. Johnson, J. Gabzdyl, M. Smith and M. Rahim, 2004, BAE Systems.

14. M.J. Peel: Dissertation in School of Materials, University of Manchester, 2005.

15. Colegrove, P.A., Painter, M., Graham, D. and Miller, T., 2nd International Symposium on FSW (cd rom), Gothenburg, Sweden, 1999.

16. P.A. Colegrove and H.R. Shercliff: Journal of Materials Processing Technology, 2005.

17. C.J. Harrison: European Union 5th Framework Project WAFS, BAE Systems, 2004.

18. QinetiQ, 2005.

19. K. Masubucci: Encyclopedia of Materials: Science and Technology, 2005, Pages 1-6 